\title{
Intravenous Alteplase Treatment of Acute Ischemic Stroke Patients Exhibiting Mild Neurological Deficits
}

\author{
Jing Sun, Hongxia Wang, Mengjiao Sun, Qinfang Xie, Ning Liu and Manxia Wang \\ Department of Neurology, Lanzhou University Second Hospital, Lanzhou, Gansu, China
}

\begin{abstract}
Alteplase is increasingly used for treating ischemic stroke cases with low NIHSS scores, but the guidelines and evidence regarding outcomes are lacking. So, the authors conducted an updated meta-analysis to better understand the effects of alteplase for the treatment of acute mild ischemic stroke. PubMed, Cochrane, EMBASE were systematically explored for all relevant investigations published as in September 2021. Study quality was assessed as per the Cochrane system criteria, and Stata 15.1 was utilised to carry out a meta-analysis. In total, 16 trials incorporating 5,846 patients were analysed (1,926 and 3,920 cases in the rt-PA and non-thrombolytic groups, respectively). The main outcome measure revealed that the treatment of rt-PA was correlated with better odds of a modified Rankin Scale (mRS) score of 0-1 relating to the non-thrombolytic group (OR = $1.12,95 \% \mathrm{Cl}=1.02-1.23, \mathrm{p}<0.05)$, and with moderate heterogeneity $\left(I^{2}=0.0 \%, p=0.930\right)$. For the secondary study outcomes, symptomatic intracranial hemorrhage incidence was 4.46 times greater in the group of rt-PA, relating to the nonthrombolytic group $(\mathrm{OR}=4.46,95 \% \mathrm{Cl}=2.75-7.23, \mathrm{p}<0.001$ ). There were no considerable differences in the mortality between the two groups $(O R=0.64,95 \% \mathrm{Cl}=0.39-1.03, \mathrm{p}>0.05)$. No significant heterogeneity was detected in secondary study outcomes. Subgroup analysis showed that the function outcomes was the best within 3-4.5 hours; and the risk and mortality of sICH were the lowest within 3-4.5 hours. Intravenous rt-PA administration is associated with improved functional outcomes at three months after the stroke in mild ischemic stroke patients.
\end{abstract}

Key Words: Acute ischemic stroke, Mild, Alteplase, Meta-analysis.

How to cite this article: Sun J, Wang H, Sun M, Xie Q, Liu N, Wang M. Intravenous Alteplase Treatment of Acute Ischemic Stroke Patients Exhibiting Mild Neurological Deficits. J Coll Physicians Surg Pak 2022; 32(03):352-358.

\section{INTRODUCTION}

Strokes are the second most prevalent reason for mortality, globally, ${ }^{1}$ and stroke incidence is steadily rising throughout the world. ${ }^{2}$ While upwards of $80 \%$ of ischemic stroke cases, primarily represent only mild symptoms, many ofthesepatients will experience a recurrent stroke or stroke progression when undergoing conservative treatment, with up to $25 \%$ of these patients being disabled or deceased upon follow-up. ${ }^{3}$ As such, effective treatments are necessary to prevent adverse outcomes in mild ischemic stroke (MIS) patients. Thrombolytic therapy can restore cerebral blood flow, reduce ischemia and improve neurological disability in acute ischemic stroke (AIS) patients. AIS patients can be treated through a standard treatment, namely alteplase-mediated intravenous thrombolysis, which is nowadays the only evidence-based (non-catheter) treatment shown to decrease stroke-associated disability rates.

Correspondence to: Manxia Wang, Department of Neurology, Lanzhou University Second Hospital, No. 82 Cuiyingmen, Lanzhou, Gansu, China

E-mail:wmx322@aliyun.com

Received: September 16, 2021; Revised: November 02, 2021; Accepted: November 24, 2021

DOI: https://doi.org/10.29271/jcpsp.2022.03.352
In general, alteplase treatment can improve functional outcomes, with efficacy increasing the earlier that treatment is initiated. ${ }^{1}$ However, MIS patients exhibiting mild neurological deficits or rapid symptom improvement generally do not undergo thrombolytic therapy, as clinicians generally assume these patients to have a better prognosis. Thrombolytic therapy is accompanied by a notable risk of bleeding events, and its efficacy is temporarily constrained. Despite these risks, MIS can markedly increase patient risk of upcoming cardiovascular incidents, including serious strokes; ${ }^{4}$ and those MIS patients exhibiting large vessel occlusion may also be at an elevated risk of stroke progression..$^{5-7}$

Alteplase has been increasingly used to treat ischemic stroke patients with low scores of NIHSS in recent years, but no specific guidelines concerning the utilisation of this medication for treating MIS exist. ${ }^{8}$ The development of such guidelines currently awaits the results of ongoing randomised controlled trials being conducted in diverse populations. While multiple prior retrospective clinical trials and a meta-analysis have found MIS patients to benefit from thrombolytic therapy, ${ }^{9-13}$ Huisa et al. observed similar functional outcomes at 90 days post-stroke in MIS patients that underwent thrombolytic and non-thrombolytic treatment, with the former being correlated with an enhanced chance of symptomatic intracranial hemorrhage. ${ }^{14}$ Other recent studies have also been published 
exploring the relationship between alteplase thrombolysis and clinical outcomes. ${ }^{15-18}$

Given the above considerations, the present authors, herein, conducted an updated meta-analysis and systematic review of all available prospective experimental researches of MIS patients who underwent alteplase thrombolysis. Trials incorporated into this analysis were those enrolling patients with NIHSS scores $\leq 6$; wherein, patients underwent intravenous thrombolytic rt-PA therapy within six hours of onset, and where therapeutic efficacy and safety were compared to those associated with non-thrombolytic therapy.

The goal of this meta-analysis was to provide a robust evidencebased foundation for the formulation of evidence-based practice protocols for treating MIS patients.

\section{METHODOLOGY}

The present meta-analysis was accomplished as per the guiding principles in the preferred reporting items for systematic reviews and meta-analyses protocols (PRISMA-P) statement 2015, using the checklist of PRISMA. ${ }^{19}$ The protocol of the present pre-specified investigation was registered with the international prospective register of systematic reviews (PROSPERO; ID: CRD42020221972). Two researchers (JS, HXW) individually searched the PubMed, Cochrane, and Embase Collaboration Central Register of Controlled Trials databanks for all relevant studies published from inception through September 2021. Discrepancies regarding study relevance were handled via discussion with a third researcher (MJS). The overall search strategy relied upon the use of Boolean operators to connect the following headings: "acute ischemic stroke," "mild stroke," "minor stroke," "alteplase," "recombinant activator of tissue-type plasminogen," and "intravascularthrombolysis."

Investigations eligible for inclusion in the present meta-analysis were: observational investigations; studies of definitively diagnosed acute ischemic stroke cases $\geq 18$ years with NIHSS scores of 0-6, exhibiting no obvious disability at the time of enrollment; studies wherein the experimental group was administered rt-PA thrombolytic therapy, and the control group was administered other non-thrombolytic treatments; and studies in which the main outcome measure was a good functional prognosis (mRS score: $0-1$ ) at three months post-stroke, with symptomatic intracranial hemorrhage incidence and mortality being the primary safety outcomes of interest. Studies were excluded if they: did not include a control group; enrolled patients with prestroke disability (mRS score: 2-6), dysphagia, acute intracranial hemorrhage on neuroimaging, or other intravenous alteplase treatment contraindications; were review articles; or did not report clinical results. Two authors (JS and HXW) independently extracted the outcome data from eligible studies, which were symptomatic intracranial hemorrhage $(\mathrm{sICH})$ based uponallavailable definitions; desirable functional information as described by an $\mathrm{mRS}$ score of $0-1$; and mortality.

The initial information for this study was a modified Rankin Scale (mRS) score of 0 or 1 (overall range: 0 [asymptomatic] to 6 [death]) at 90 days of post-enrollment, consistent with a favourable functional after adjusting for age, the time between symptoms onset and treatment, and baseline NIHSS score was the primary study outcome in this analysis. The primary safety endpoint was $\mathrm{SICH}$, the definition of which varied between studies, with neurological and stroke-related death during 90 days and the intensity; and extent for all adverse incidents also being analysed.

The quality of included experimental investigation investigations was assessed utilising the scoring system of NewcastleOttawa scale (NOS), ${ }^{20}$ with studies being scored based upon selection, comparability, and outcomes. Possible scores ranged from $0-9$, with a score of 7 or greater being indicative of high quality research.

Data entry was independently performed by two reviewers. After cross-checking was performed to ensure data accuracy, Stata 15.1 was utilised to conduct this meta-analysis. Categorical data were reported as odds ratio (ORs) with $95 \%$ confidence intervals (Cl). The $I^{2}$ statistic was employed when assessing heterogeneity among studies, with the models of fixed-effects being utilised for analyses when heterogeneity was limited $\left(I^{2}<50 \%, p>0.1\right)$, and random-effects models otherwise being utilised when significant statistical heterogeneity was present $\left(I^{2}>50 \%, p<0.1\right)$. Sources of heterogeneity were also evaluated, with only descriptive analyses being performed when heterogeneity was not statistical. Egger's measurement and Begg's measurement were conducted, with funnel plots being used to test for possible publication bias; $p<0.05$ was the significance threshold.

\section{RESULTS}

The elemental research strategy determined 306 investigations, of which 16 incorporating 5,846 cases were included in this final assessment. The rt-PA and non-thrombolytic groups in these studies enrolled 1,926 and 3,920 patients, respectively. Of these investigations, 6 were executed in Europe, 5 in the USA, 3 in Asia, and the remainder were performed in Australia. Baseline study characteristics are compiled in Table I. When studies were evaluated using the NOS criteria, 12 were identified as being of high quality (NOS $\geq 7$ ), while three studies scored 3 points on this scale. ${ }^{12,21,22}$

All 16 studies reported the number of acute MIS patients with mRS scores of $0-1$ on day 90 post-rt-PA treatment. The overall effect of mRS $0-1$ at 90 days $(Z=2.45, p=0.014)$ was statistically significant, suggesting that patients who underwent thrombolytic therapy had better outcomes at 3 months posttreatment relating to patients that underwent non-thrombolytic treatment $(\mathrm{OR}=1.12,95 \% \mathrm{Cl}=1.02-1.23$, Figure 1$)$. Moderate heterogeneity was detected pertaining to this endpoint $\left(l^{2}=0.0 \%, p>0.1\right)$, and a fixed-effects model was used forthese analyses.

The incidence of $\mathrm{SICH}$ in MIS cases was published in 12 studies. No heterogeneity pertaining to this endpoint was detected $\left(\mathrm{I}^{2}=\right.$ $0.0 \%, p=0.747$ ), so a model fixed-effects was used for subsequent analysis. 
Table I: Included study characteristics.

\begin{tabular}{|c|c|c|c|c|c|c|c|c|c|c|}
\hline \multicolumn{11}{|c|}{ Rt-PA / No rt-PA } \\
\hline $\begin{array}{l}\text { Author } \\
\text { Year }\end{array}$ & Country & $\begin{array}{l}\text { Research } \\
\text { method }\end{array}$ & \begin{tabular}{|c|} 
Time from \\
onset to \\
treatment \\
(h) \\
\end{tabular} & $\begin{array}{c}\text { Baseline } \\
\text { NIHSS } \\
\text { score }\end{array}$ & Cases & Men & Age (year) & $\begin{array}{l}\text { mRS 0-1 } \\
\text { at } 3 \\
\text { months }\end{array}$ & SICH & $\begin{array}{l}\text { Mortality } \\
\text { at } 3 \\
\text { months }\end{array}$ \\
\hline $\operatorname{Lan}^{17} 2020$ & China & $\begin{array}{c}\text { Retrospective } \\
\text { cohort }\end{array}$ & $\leq 4.5$ & $\leq 5$ & $109 / 109$ & $74 / 76$ & $\begin{array}{r}66.4 \pm 11.1 / \\
62.6 \pm 10.7\end{array}$ & $85 / 99$ & $4 / 1$ & $0 / 0$ \\
\hline Tsivgoulis $^{19} 2020$ & America & Non-RCT & $\leq 4.5$ & $\leq 6$ & $162 / 174$ & $100 / 85$ & $62.5 \pm 14.9 / 64.5 \pm 15.1$ & $\begin{array}{l}118 / \\
107\end{array}$ & $6 / 2$ & $12 / 15$ \\
\hline $\begin{array}{l}\text { Haeberlin }^{16} \\
2020\end{array}$ & Switzerl & $\begin{array}{c}\text { Retrospective } \\
\text { cohort }\end{array}$ & $\leq 6$ & $\leq 6$ & $108 / 262$ & 79/171 & $64 \pm 14 / 63 \pm 14$ & $98 / 235$ & $14 / 9$ & $0 / 0$ \\
\hline Merlino $^{18} 2020$ & Italy & $\begin{array}{c}\text { Retrospective } \\
\text { cohort }\end{array}$ & $\leq 4.5$ & $\leq 5$ & $113 / 276$ & $67 / 168$ & $\begin{array}{l}68.2 \pm 12.0 / \\
68.7 \pm 14.2\end{array}$ & 98/195 & $5 / 3$ & $1 / 3$ \\
\hline Khatri 2018 & America & RCT & $\leq 3 \mathrm{~h}$ & $\leq 5$ & $156 / 157$ & $77 / 92$ & $62 \pm 14 / 61 \pm 13$ & $122 / 128$ & $5 / 0$ & $1 / 0$ \\
\hline Chen $^{21} 2017$ & China & $\begin{array}{c}\text { Retrospective } \\
\text { cohort }\end{array}$ & $\leq 4.5$ & $\leq 5$ & $134 / 249$ & $86 / 159$ & $\begin{array}{c}62.3 \pm 10.5 / 63.2 \pm \\
10.6\end{array}$ & $104 / 173$ & $1 / 0$ & $2 / 3$ \\
\hline $\mathrm{Ng}^{12} 2016$ & Australia & $\begin{array}{c}\text { Retrospective } \\
\text { cohort }\end{array}$ & $\leq 4.5$ & $\leq 3$ & $34 / 39$ & - & $74.5 \pm 11.9$ & $31 / 28$ & $0 / 0$ & ( \\
\hline Khatri 2015 & America & RCT & $\leq 6$ & $\leq 5$ & $55 / 51$ & $28 / 31$ & $82 / 81$ & $46 / 33$ & 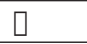 & 0 \\
\hline Heldne 2015 & Switzerland & Cohort & $\leq 4.5$ & $\leq 5$ & $41 / 47$ & $22 / 33$ & $66.3 \pm 12.9 / 68 \pm 14.1$ & $25 / 20$ & $2 / 0$ & $3 / 3$ \\
\hline Choi $^{11} 2015$ & Korea & $\begin{array}{c}\text { Retrospective } \\
\text { cohort }\end{array}$ & $\leq 4.5$ & $\leq 5$ & $144 / 224$ & 93/ 153 & $\begin{array}{c}63.9 \pm 13.7 \\
163.8 \pm 14.0\end{array}$ & $\begin{array}{l}104 / \\
134\end{array}$ & $8 / 6$ & $2 / 23$ \\
\hline Logallo 2014 & Norway & $\begin{array}{c}\text { Retrospective } \\
\text { cohort }\end{array}$ & $\leq 4.5$ & $\leq 5$ & $158 / 1633$ & $105 / 985$ & $67.3 \pm 13.9 / 69.9 \pm 14.1$ & $68 / 506$ & $3 / 1$ & 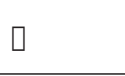 \\
\hline $\mathrm{Nesi}^{22} 2014$ & Italy & $\begin{array}{c}\text { Retrospective } \\
\text { cohort }\end{array}$ & $\leq 3$ & $\leq 6$ & $47 / 81$ & $33 / 59$ & $\begin{array}{l}65.4 \pm 11.8 / \\
66.9 \pm 10.5 \\
\end{array}$ & $41 / 67$ & $0 / 0$ & $0 / 0$ \\
\hline $\begin{array}{l}\text { Greisenegger }^{10} \\
2014\end{array}$ & Australia & $\begin{array}{c}\text { Retrospective } \\
\text { cohort }\end{array}$ & $\leq 4.5$ & $\leq 5$ & $445 / 445$ & $259 / 259$ & $69.6 \pm 12.6 / 70 \pm 11.9$ & $329 / 284$ & $11 / 0$ & ( \\
\hline Urra $^{9} 2013$ & Spain & Non-RCT & $\leq 4.5$ & $\leq 5$ & $119 / 84$ & $82 / 52$ & $\begin{array}{c}68.8 \pm 13.8 / 69.0 \\
\pm 13.2\end{array}$ & $99 / 68$ & $0 / 0$ & $2 / 3$ \\
\hline Branko $^{14} 2012$ & America & $\begin{array}{c}\text { Retrospective } \\
\text { cohort }\end{array}$ & $\leq 3$ & $\leq 5$ & $59 / 74$ & $36 / 43$ & $66.5 \pm 16.4 / 70.1 \pm 14.5$ & $34 / 51$ & $3 / 0$ & $3 / 3$ \\
\hline Khatri $^{23} 2010$ & America & Retrospective & $\leq 3$ & $\leq 5$ & $42 / 16$ & $30 / 10$ & $\begin{array}{l}66.2 \pm 12.0 / \\
66.2 \pm 12.0\end{array}$ & $33 / 13$ & $1 / 0$ & $1 / 0$ \\
\hline
\end{tabular}

Table II: Subgroup analysis results according to the duration from stroke onset to thrombolysis.

\begin{tabular}{|c|c|c|c|c|c|c|}
\hline \multirow[b]{2}{*}{ mRS $0-1$ at 90 days } & \multicolumn{2}{|c|}{ 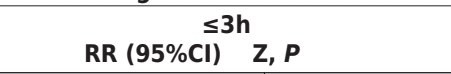 } & \multicolumn{2}{|c|}{$\begin{array}{c}3-4.5 \mathrm{~h} \\
\operatorname{RR}(95 \% \mathrm{Cl}) \mathrm{Z}, \mathrm{P}\end{array}$} & \multicolumn{2}{|c|}{$\begin{array}{r}4.5-6 \mathrm{~h} \\
\operatorname{RR}(95 \% \mathrm{CI}) \text { Z, P }\end{array}$} \\
\hline & $0.97(0.85,1.11)$ & $0.39,0.699$ & $1.10(1.03,1.17)$ & $2.85,0.004$ & $1.04(0.89,1.21)$ & $0.48,0.633$ \\
\hline $\mathrm{SICH}$ & $5.98(1.20,29.91)$ & $2.18,0.029$ & $4.36(2.39,7.96)$ & $4.79,0.000$ & $3.46(1.54,7.76)$ & $3.00,0.003$ \\
\hline Mortality & $1.45(0.41,5.16)$ & $0.58,0.564$ & $0.57(0.35,0.95)$ & $2.15,0.031$ & - & - \\
\hline
\end{tabular}

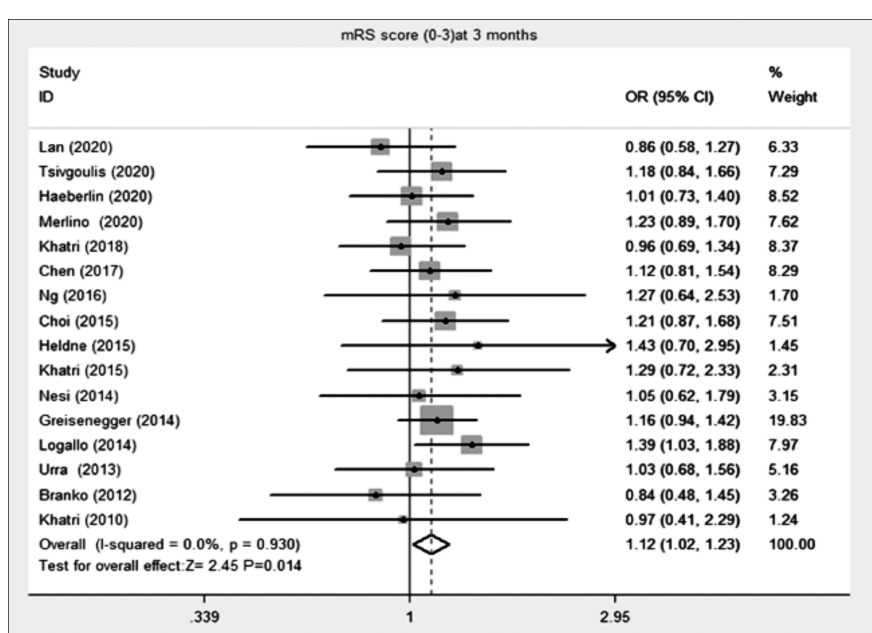

Figure 1: Forest plots for the initial endpoint of desirable data (mRS score: $0-1$ ) at 90 days of posttreatment in acute mild stroke patient.

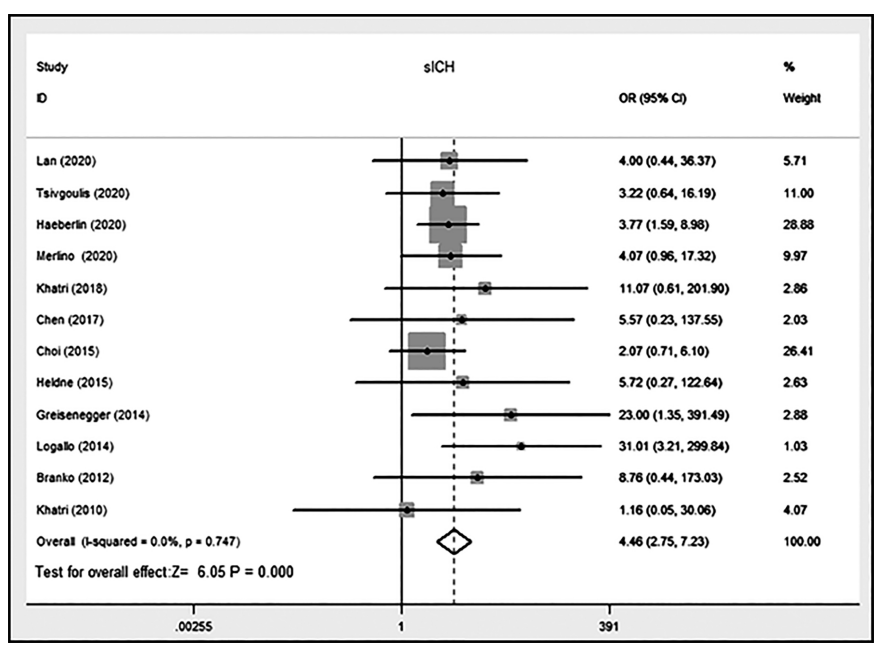

Figure 2: Forest plots for symptomatic intracranial hemorrhage (sICH) incidence in acute mild stroke patients. 


\begin{tabular}{|c|c|c|}
\hline & & \\
\hline Study & & $\%$ \\
\hline ID & OR $(95 \% \mathrm{Cl})$ & Weight \\
\hline Tsingoulis (2020) & $0.86(0.39,1.89)$ & 30.55 \\
\hline Merlino (2020) & $0.81(0.08,7.91)$ & 3.94 \\
\hline Khatri (2018) & $3.02(0.12,74.68)$ & 1.13 \\
\hline Chen (2017) & $1.24(0.20,7.51)$ & 4.73 \\
\hline Heldne (2015) & $1.15(0.22,5.99)$ & 5.97 \\
\hline Choi (2015) & $0.14(0.03,0.58)$ & 38.46 \\
\hline Urra (2013) & $0.47(0.08,2.88)$ & 7.83 \\
\hline Branko (2012) & $1.25(0.24,6.44)$ & 5.81 \\
\hline Khatri (2010) & $1.16(0.05,30.06)$ & 1.59 \\
\hline Overall (1-squared $=0.0 \%, p=0.459$ ) & $0.64(0.39,1.03)$ & 100.00 \\
\hline Test for overall effect: $Z=1.85 \quad P=0.064$ & & \\
\hline 0134 & 4.7 & \\
\hline
\end{tabular}

Figure 3: Forest plots for mortality in all patients for acute mild stroke.

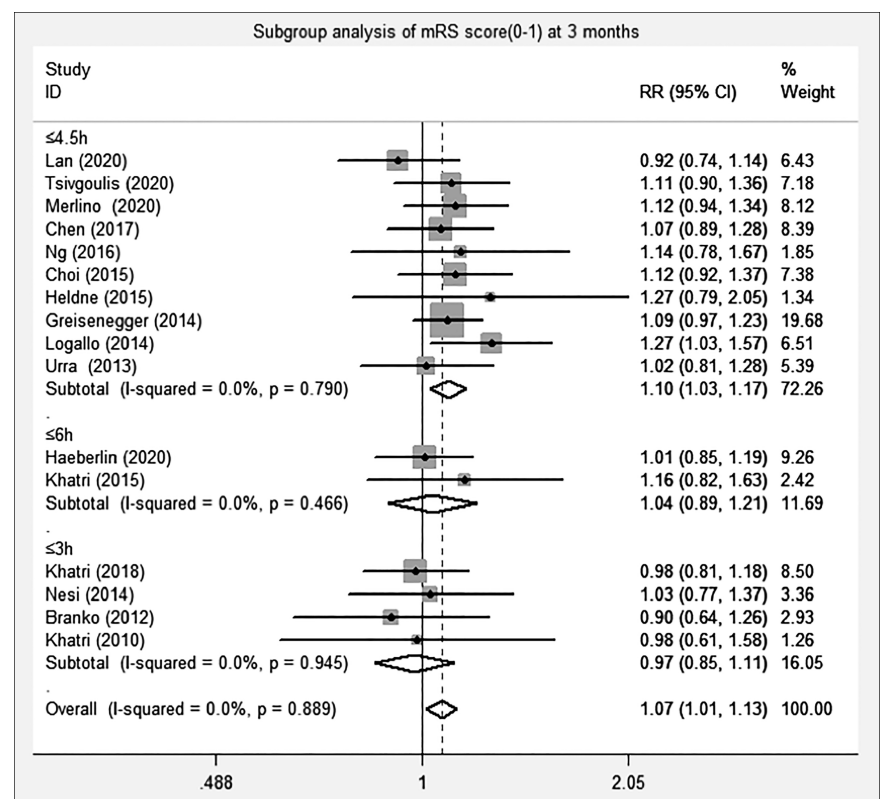

Figure 4: Subgroup analysis of $\mathrm{mRS}$ score (0-1) at 3 months.

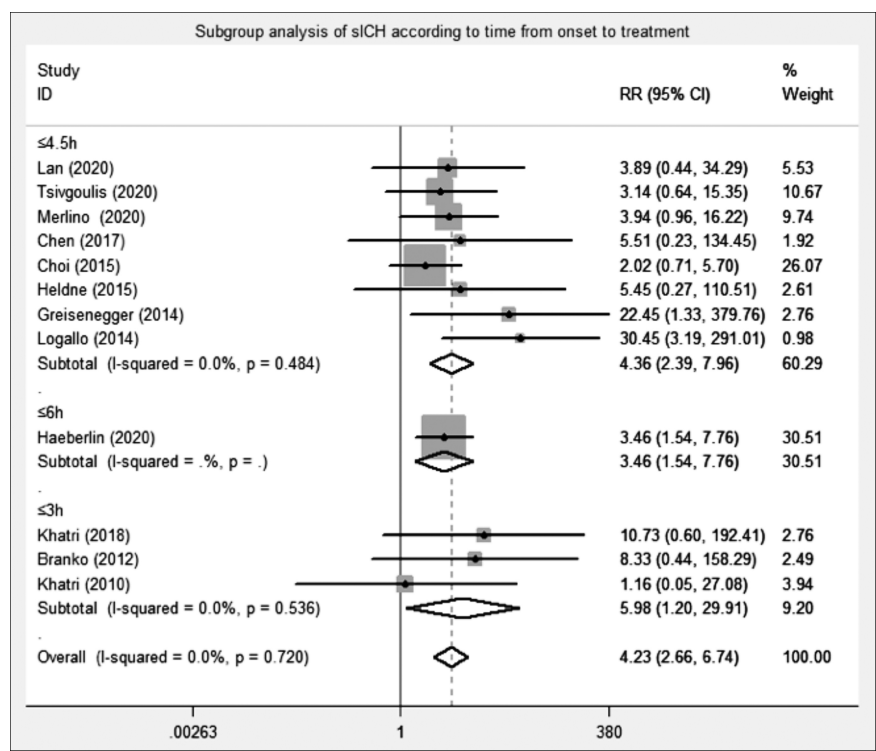

Figure 5: Subgroup analysis of sICH according to the time from onset to treatment.

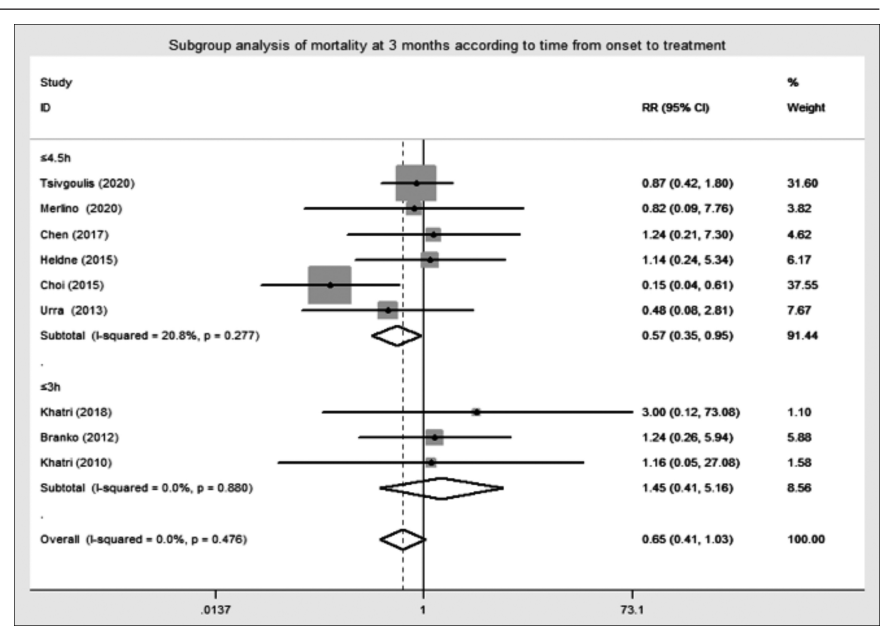

Figure 6: Subgroup analysis of morality at 3 months according to time from onset to treatment.

The overall effect ( $z=6.05, p<0.001$ ) was statistically significant (Figure 2), revealing that this risk of $\mathrm{SICH}$ was 4.46 times higher in patients that underwent rt-PA treatment relating to patients that underwent non-thrombolytic treatment $(\mathrm{OR}=4.46,95 \% \mathrm{Cl}=2.75-7.23)$.

Mortality within a 3-month follow-up period was reported in 9 studies. No heterogeneity was detected pertaining to this endpoint $\left(I^{2}=0.0 \%, p=0.459\right)$, so assessments were accomplished utilising a model of fixed-effects. The overall effect ( $z$ $=1.85, p=0.064$ ) was not statistically considerable, indicating that rt-PA and non-thrombolytic treatments were not correlated with differences in mortality of the patient $(\mathrm{OR}=$ $0.64,95 \% \mathrm{Cl}=0.39-1.03$, Figure 3 ).

The potential publication was next assessed using funnel plots. Funnel plots pertaining to $\mathrm{sICH}$ and $\mathrm{mRS}$ score at 3 months were roughly symmetrical, consistent with a lack of significant publication bias. Begg's measurement and Egger's measurement similarly exhibited no evidence of publication bias pertaining to favourable mRS score at 3 months (Begg's Test $\square p=0.685$, Egger's test: $p=0.115$ ), sICH (Begg's Test: $p=0.631$, Egger's test: $p=0.114$ ), and mortality (Begg's Test: $p=0.754$, Egger's test: $p=0.448$ ) as shown in supplementary materials). The number of studies on mortality is less than 10 , so funnel chart is not suitable for publication bias detection.

To a large extent, the duration from stroke to thrombolysis usually affects the therapeutic effect of stroke. In order to explore the effect of thrombolysis duration on stroke recovery, subgroup analysis was carried out according to the duration from onset to thrombolysis. The results showed that the thrombolytic effect (mRS $0-1$ at 90 days) was the best within 4.5 hours $(\mathrm{RR}=1.07,95 \% \mathrm{Cl}=1.01-1.13)$ (Figure 4, Table II). Subgroup analysis of $\mathrm{sICH}$ showed that the faster thrombolysis, the greater the possibility of $\mathrm{sICH}(\leq 3 \mathrm{~h}$, $\mathrm{RR}=5.98,95 \% \mathrm{Cl}=1.20-29.91 ; \leq 4.5 \mathrm{~h}, \mathrm{RR}=4.36,95 \% \mathrm{Cl}=$ 2.39-7.96; $\leq 6 \mathrm{~h}, \mathrm{RR}=3.46,95 \% \mathrm{Cl}=1.54-7.76$ ) (Figure 5, Table II). Subgroup analysis of post-thrombolytic mortality 
showed that thrombolytic mortality was lower at 4.5 hours $(\mathrm{RR}=0.57,95 \% \mathrm{Cl}=0.35-0.95)$ and increased within 3 hours $(\mathrm{RR}=1.45,95 \% \mathrm{Cl}=0.41-5.16)$ (Figure 6, Table II).

\section{DISCUSSION}

Herein, it was determined that the administration of intravenous rt-PA therapy within 6 hours after stroke occurrence was associated with improved functional outcomes in 90 days of post-treatment. Relating to non-thrombolytic treatment, alteplase thrombolysis did not significantly increase patient mortality, although it was associated with an increased risk of sICH. The duration from stroke occurrence to thrombolysis affects the functional recovery, sICH and mortality of post-treatment. Within 4.5 hours, the functional recovery was the fastest, and the risk of mortality and $\mathrm{sICH}$ was the lowest. However, the risk of mortality and $\mathrm{sICH}$ will increase within 3 hours. Therefore, the thrombolysis duration should be controlled in 3-4.5 hours.

Uncertainty regarding the relative benefit of intravenous rtPA treatment has risen following the publication of observational studies reporting greater clinical benefit coinciding with increased sICH risk among the patients undergoing such treatment relating to individuals undergoing nonthrombolytic care. The present meta-analysis confirmed these findings, revealing alteplase treatment to be associated with elevated $\mathrm{sICH}$ risk $(\mathrm{OR}=4.46 ; 95 \%$ confidence interval, 2.75 - 7.23). Khatri et al. included a small number of AIS cases with mild symptoms (just $9.3 \%$ of overall patients), potentially masking any increased risk of bleeding associated with alteplase treatment. ${ }^{23}$ In the study published by Branko et al., ${ }^{14}$ the baseline patient groups were unbalanced, potentially impacting study findings. The NIHSS scores of patients with large vessels or distal occlusion in the alteplase group, in the study conducted by Tsivgoulis et al., were higher for patients in the alteplase group relating to the control group. Thus, increasing the risk of sICH in the former group. ${ }^{19}$ The PRISMS study was a randomised multicentre clinical trial appraising the therapeutic efficacy of alteplase, ${ }^{15}$ As the study was subject to early termination, however, it did not yield substantial-high-quality evidence. Among a total of 5,910 patients with NIHSS scores of 0-5 in a national US registry that underwent routine alteplase treatment, $1.8 \%$ of patients experienced $\mathrm{sICH}^{24}$ In the present analysis, the absolute risk of sICH associated with alteplase was 3.3\% (63/1926), which was higher than $1.8 \%$, but lower than the $6-7.7 \%$ sICH risk in individuals with higher NIHSS scores. ${ }^{25,26}$ This risk of bleeding is acceptable. Prior analyses of observational cohorts that underwent non-thrombolytic treatment may have incorporated individuals with more severe disease, given recent trends towards the increasingly prevalent utilisation of alteplase to treat minor stroke patients in clinical settings. $^{27,28}$
The outcomes of the present research are in a desirable agreement with those of a prior meta-analysis on this topic that similarly found intravenous alteplase to be correlated with improved functional data in acute mild stroke cases. While such treatment enhanced the chance of sICH, the risk was very low and not associated with any increase in mortality. ${ }^{13}$ The present meta-analysis included significantly more MIS patients than did the prior analysis (5,846 vs. 1,591 patients), incorporating more studies and analysing outcomes from cases with a large vessel or distal occlusion stroke subtypes. The heterogeneity correlated with the analyses of this study was low, and no evidence of publication bias was realised.

There are certain limitations to this analysis. For one, only English studies were included in this analysis of this study, and studies published in other languages may, therefore, have been overlooked. Second, treatment initiation times and baseline NIHSS scores varied among the 16 included studies (Table I), potentially impacting the thrombolytic efficacy of alteplase. The analyses of this study also did not distinguish the proportion of individuals with particular stroke subtypes, and the 16 studies included herein enrolled patients with different stroke etiology. Different ischemic stroke subtypes, such as large vessel disease, small vessel stenosis, and cryptogenic stroke may have impacted alteplase treatment responses, influencing perceived net benefit. In addition, as the studies included herein were observational, selection bias has the potential to have influenced these results.

Overall, strengths of these analyses include the comprehensive literature review, clear inclusion criteria enabling focus on the patients most likely to benefit from alteplase treatment, risk assessment of bias, use of a scoring method to evaluate the strength of the underlying evidence, and an overview of the risk-benefit ratio associated with alteplase use.

\section{CONCLUSIONS}

These results indicate that acute mild ischemic stroke cases exhibited improved 90-day favourable functional outcomes following alteplase treatment relative to controls. However, such treatment was also correlated with an enhanced chance of $\mathrm{sICH}$.

As the analyses did not include randomised controlled trials and the results are susceptible to selection bias, further large-scale prospective randomised analyses are necessary to definitively establish the efficacy and safety of intravenous alteplase thrombolysis for treating the acute mild ischemic stroke.

\section{FUNDING:}

This work was supported by the Talent Innovation and Entrepreneurship Project of Lanzhou City, Gansu Province (2020-RC-47). 


\section{PATIENTS' CONSENT:}

This study is a meta-analysis, and all analyses are based on previously published studies; thus the patients' consent is not applicable.

\section{CONFLICT OF INTEREST:}

The authors declared no conflict of interest.

\section{AUTHORS' CONTRIBUTION:}

JS: Retrieved literatures, study design, acquisition, analysis and drafted the manuscript.

HW: Screened the literature and analysed the statistical data.

MS: Analysed data and modified the manuscript.

QX: Made pictures, interpretation of results.

NL: Analysed data and made pictures.

MW: Study design and censored the article.

\section{REFERENCES}

1. Powers WJ, Rabinstein AA, Ackerson T, Adeoye OM, Bambakidis NC, Becker K, et al. Guidelines for the Early management of patients with acute ischemic stroke: 2019 update to the 2018 guidelines for the early management of acute ischemic stroke: A guideline for healthcare professionals from the american heart association/ American stroke association. Stroke 2019; 50(12):e344-e418. doi:10.1161/ STR.0000000000000211.

2. Thrift AG, Thayabaranathan T, Howard G, Howard VJ, Rothwell PM, Feigin VL, et al. Global stroke statistics. Int J Stroke 2017; 12(1):13-32. doi:10.1177/17474930166 76285.

3. Yu AYX, Hill MD, Coutts SB. Should minor stroke patients be thrombolysed? A focused review and future directions. Int J Stroke 2015; 10(3):292-7. doi:10.1111/ijs.12426.

4. Amarenco P, Lavallée PC, Monteiro Tavares L, Labreuche J, Albers GW, Abboud $\mathrm{H}$, et al. Five-year risk of stroke after TIA or minor ischemic stroke. New Eng J Med 2018; 378(23):2182-90. doi:10.1056/NEJMoa1802712.

5. Rajajee V, Kidwell C, Starkman S, Ovbiagele B, Alger JR, Villablanca $\mathrm{P}$, et al. Early MRI and outcomes of untreated patients with mild or improving ischemic stroke. Neurology 2006; 67(6): 980-4. doi: 10.1212/01.wnl.0000237520. 88777.71.

6. Nedeltchev K, Schwegler B, Haefeli T, Brekenfeld C, Gralla J, Fischer $U$, et al. Outcome of stroke with mild or rapidly improving symptoms. Stroke 2007; 38(9): 2531-5. doi: 10.1161/STROKEAHA.107.482554.

7. Smith EE, Fonarow GC, Reeves MJ, Cox M, Olson DM, Hernandez $A F$, et al. Outcomes in mild or rapidly improving stroke not treated with intravenous recombinant tissue-type plasminogen activator: Findings from get with the guidelines-stroke. Stroke 2011; 42(11): 3110-5. doi:10. 1161/ STROKEAHA.111.613208.

8. Powers WJ, Rabinstein AA, Ackerson T, Adeoye OM, Bambakidis NC, Becker K, et al. 2018 guidelines for the early management of patients with acute ischemic stroke: $A$ guideline for healthcare professionals from the american heart association/American Stroke Association. Stroke 2018; 49(3). doi:10.1161/STR.0000000000000158.
9. Urra X, Ariño H, Llull L, Amaro S, Obach V, Cervera Á, et al. The outcome of patients with mild stroke improves after treatment with systemic thrombolysis. PloS One 2013; 8(3):e59420. doi:10.1371/journal.pone.0059420.

10. Greisenegger S, Seyfang L, Kiechl S, Lang W, Ferrari J. Thrombolysis in patients with mild stroke: Results from the austrian stroke unit registry. Stroke 2014; 45(3): 765-9. doi:10.1161/STROKEAHA.113.003827.

11. Choi JC, Jang MU, Kang K, Park JM, Ko Y, Lee SJ, et al. Comparative effectiveness of standard care with IV thrombolysis versus without IV thrombolysis for mild ischemic stroke. J Am Heart Assoc 2015; 4(1):e001306. doi:10.1161/JAHA.114.000596.

12. Ng FC, Coote S, Frost T, Bladin C, Choi PM. Utility of computed tomographic perfusion in thrombolysis for minor stroke. Stroke 2016; 47(7):1914-6. doi:10.1161/ STROKEAHA.116.013021.

13. You S, Saxena A, Wang X, Tan W, Han Q, Cao Y, et al. Efficacy and safety of intravenous recombinant tissue plasminogen activator in mild ischaemic stroke: A meta-analysis. Stroke Vasc Neurol 2018d0.1136/svn-2017- 000106.

14. Huisa BN, Raman R, Neil W, Ernstrom K, Hemmen TM. Intravenous tissue plasminogen activator for patients with minor ischemic stroke. J Stroke Cerebrovasc Dis 2012; 21(8): 732-6. doi:10.1016/j.jstrokecerebrovasdis.2011. 03.009.

15. Khatri P, Kleindorfer DO, Devlin T, Sawyer RN, Starr M, Mejilla J, et al. Effect of alteplase vs. aspirin on functional outcome for patients with acute ischemic stroke and minor nondisabling neurologic deficits: The PRISMS randomised clinical trial. JAMA 2018; 320(2):156-66. doi:10.1001/ jama.2018.8496.

16. Haeberlin MI, Held U, Baumgartner RW, Georgiadis D, Valko PO. Impact of intravenous thrombolysis on functional outcome in patients with mild ischemic stroke without large vessel occlusion or rapidly improving symptoms. Int J Stroke 2020; 15(4):429-37. doi:10.1177/17474930198 74719.

17. Lan L, Rong X, Shen Q, Gong H, Li X, Wang H, et al. Effect of alteplase versus aspirin plus clopidogrel in acute minor stroke. Int J Neuroscience 2020; 130(9):857-64. doi:10. 1080/00207454.2019.1707822.

18. Merlino G, Smeralda C, Lorenzut S, Gigli GL, Surcinelli A, Valente $M$. To treat or not to treat: Importance of functional dependence in deciding intravenous thrombolysis of "mild stroke" patients. J Clin Medicine 2020; 9(3): 768. doi:10. 3390/jcm9030768.

19. Tsivgoulis G, Goyal N, Katsanos AH, Malhotra K, Ishfaq MF, Pandhi $A$, et al. Intravenous thrombolysis for large vessel or distal occlusions presenting with mild stroke severity. Euro Neurol 2020; 27(6):1039-47.doi:10.1111/ene.14199.

20. Lo CKL, Mertz D, Loeb M. Newcastle-ottawa scale: Comparing reviewers' to authors' assessments. BMC Med Res Methodol 2014; 14:45. doi:10.1186/1471-2288-14-45.

21. Chen W, Pan Y, Zhao X, Liu L, Li H, Liao X, et al. Intravenous thrombolysis in Chinese patients with different subtype of mild stroke: Thrombolysis in patients with mild stroke. Sci Rep 2017; 7(1):2299. doi:10.1038/s41598- 017-02579-2.

22. Nesi M, Lucente $G$, Nencini $P$, Fancellu L, Inzitari D. Aphasia predicts unfavorable outcome in mild ischemic stroke patients and prompts thrombolytic treatment. J Stroke Cere- 
brovascular Dis 2014; 23(2):204-8.doi:10.1016/j. jstrokecerebrovasdis.2012.11.018

23. Khatri P, Kleindorfer DO, Yeatts SD, Saver JL, Levine SR, Lyden PD, et al. Strokes with minor symptoms: an exploratory analysis of the National Institute of Neurological Disorders and Stroke recombinant tissue plasminogen activator trials. Stroke 2010; 41(11): 2581-6.doi:10.1161/STROKEAHA.110.593632.

24. Romano JG, Smith EE, Liang L, Gardener H, Camp S, Shuey $L$, et al. Outcomes in mild acute ischemic stroke treated with intravenous thrombolysis: a retrospective analysis of the Get With the Guidelines-Stroke registry. JAMA Neurol 2015; 72(4):423-31.doi:10.1001/jamaneurol.2014.4354.

25. Wardlaw JM, Murray V, Berge E, Del Zoppo G, Sandercock P, Lindley $\mathrm{RL}$, et al. Recombinant tissue plasminogen activator for acute ischaemic stroke: an updated systematic review and meta-analysis. Lancet 2012; 379(9834):2364-72.
doi:10.1016/S0140-6736(12)60738-7.

26. Wahlgren N, Ahmed N, Dávalos A, Ford GA, Grond M, Hacke $W$, et al. Thrombolysis with alteplase for acute ischaemic stroke in the Safe Implementation of Thrombolysis in Stroke-Monitoring Study (SITS-MOST): an observational study. Lancet 2007; 369(9558): 275-82.

27. Schwamm LH, Ali SF, Reeves MJ, Smith EE, Saver JL, Messe $\mathrm{S}$, et al. Temporal trends in patient characteristics and treatment with intravenous thrombolysis among acute ischemic stroke patients at Get With The Guidelines-Stroke hospitals. Circ Cardiovasc Qual Outcomes 2013; 6(5):543-9. doi:10.1161/CIRCOUTCOMES.111.000303.

28. Asdaghi N, Wang K, Ciliberti-Vargas MA, Gutierrez CM, Koch $\mathrm{S}$, Gardener $\mathrm{H}$, et al. Predictors of Thrombolysis Administration in Mild Stroke: Florida-Puerto Rico Collaboration to Reduce Stroke Disparities. Stroke 2018; 49(3):638-45. doi:10.1161/STROKEAHA.117.019341. 